\title{
Slower Implicit Categorical Learning in Adult Poor Readers
}

\author{
Anne J. Sperling \\ Zhong-Lin Lu \\ Franklin R. Manis \\ University of Southern California \\ Los Angeles, California
}

We investigated the relationship between reading and explicit and implicit categorical learning by comparing university students with poor reading to students with normal reading abilities on two categorical learning tasks. One categorical learning task involved sorting simple geometric shapes into two groups according to a unidimensional rule. The sorting rule was easily stated by the participants, consistent with explicit learning, and all participants attained criterion levels of performance. The second task involved the integration of features on different dimensions with a more complex rule that could not be described by participants, even though most could attain criterion levels of performance consistent with implicit learning. Poor readers performed as well as those without reading problems in explicit learning but not in implicit learning. Implicit learning was correlated with word reading, phonological decoding, and orthographic skill, independent of verbal ability. We consider the role of implicit learning in reading, and how a deficit could impair phonological and orthographic representation and processing.

Annals of Dyslexia, Vol. 54, No. 2, 2004

Copyright @2004 by The International Dyslexia Association ${ }^{\circledR}$ ISSN 0736-9387 


\section{INTRODUCTION}

Authors in the learning and memory literature often compare two forms of learning: implicit and explicit. Learning may be considered implicit when proficiency exists despite the absence of conscious awareness (Ashby, Alfonso-Reese, Turken, \& Waldron, 1998; Reber, 1993). Although a learner may perform well above chance on a test requiring understanding of rules or patterns, when questioned, he or she may offer only a vague sense of what was learned. Such implicit or procedural learning (as it is sometimes called in the literature) contrasts with explicit or declarative learning, where proficiency is obtained through conscious awareness of learning a rule or pattern (Ashby \& Ell, 2001; Keri, 2003; Knowlton \& Squire, 1993). In the case of explicit learning, a learner can clearly articulate the rule or pattern that was used in the learning task (Ashby et al., 1998).

The process of learning to read seems to involve both explicit and implicit learning (Ehri, Nunes, Stahl, \& Willows, 2001; Rayner, Foorman, Perfetti, Pesetsky, \& Seidenberg, 2001; Share, 1995). In a recent comparison of various forms of reading instruction, Ehri et al. (2001) found that systematic instruction in phonics-explicitly teaching beginning readers to relate letters and sounds and to segment words into component unitshelped beginning readers far better than less direct approaches such as whole-language methods, which assume learners will absorb the letter/sound associations more indirectly through constant exposure. After initial stages of explicit instruction, however, learning can be viewed as taking on a more implicit character (Ehri, 1990; Share, 1995). Not all letter-sound associations are easy to state explicitly or are completely consistent in many of the world's orthographies (Steffler, 2001), nor are they often explicitly taught past the early stages of instruction. In languages such as English, Danish, and French, there are many exceptions to the grapheme-phoneme correspondence rules (such as colonel and yacht), yet with experience, most learners eventually become fluent in word reading. Presumably, some portion of this learning is implicit in nature. Even in languages with highly regular grapheme-phoneme correspondences (e.g., Finnish, German, Italian, and Spanish), the attainment of fluent visual word recognition may involve implicit learning processes.

In a discussion of the role of implicit cognition in spelling development, Steffler (2001) suggested that while some spelling conventions may be easy to learn and remember explicitly as 
rules (such as, for example, the English rule, " $i$ before $e$ except after $c^{\prime \prime}$ ), other spelling conventions (such as knowing when to use -tion versus -sion in English words) may not be as clearly explicable as a rule, despite being easily applied by a proficient speller. Attaining spelling proficiency would seem fruitless without a combination of explicit and implicit processes. In a discussion of Karmiloff-Smith's developmental model (1992) of how children's knowledge representation goes through cyclical changes until adult proficiency is attained, Steffler describes how learning is viewed as a process of rendering knowledge representations more accessible and flexible, which in the adult literature would seem to be associated with a more implicit representation. Steffler notes, however, that definitions can differ dramatically between the child and adult literatures: KarmiloffSmith's model describes the representational transfer as going from "implicit" to "explicit." Regardless of the difference in terminology, the important unifying concept is that proficiency and fluency require that knowledge representations become more automatic and flexible. This paper defines implicit learning as involving knowledge representation that is automatic and more or less unconscious.

The importance of implicit learning to reading is bolstered by connectionist modeling simulations of reading. According to connectionist models (Harm \& Seidenberg, 1999; Seidenberg \& McClelland, 1989), although some initial orthographyphonology connections may be 'taught' explicitly, the majority of such learning occurs through coincidence detection of probabilistic properties in the input, and is thus implicit. It is possible that orthography to meaning computations also involve implicit learning (Harm \& Seidenberg, 2004). Dual-route models also suggest a split between explicit and implicit learning as embodied in the two reading mechanisms of explicit rule-based phonological decoding and direct lexical retrieval (Coltheart, Curtis, Atkins, \& Haller, 1993). In dual-route models as well, learning to read becomes increasingly a matter of implicit learning of print-to-meaning associations.

Although most learners master both explicit and implicit aspects of learning to read, attaining both automatized phonological decoding and recognition of orthographic patterns, individuals diagnosed with developmental dyslexia experience unusual delays in the process of learning to read. Several recent theoretical accounts of dyslexia invoke a fundamental deficit in the processing and representation of phonological information (Harm \& Seidenberg, 1999; Manis, Seidenberg, Doi, McBride- 
Chang, \& Petersen, 1996; Rayner, et al., 2001; Share, 1995; Stanovich \& Siegel, 1994; Wagner \& Torgesen, 1987) due to flawed analysis of the sound structure of words and/or inaccurate phonological representations of words (Swan \& Goswami, 1997). Even where it can be demonstrated that children with dyslexia acquire explicit knowledge of grapheme-phoneme correspondences and develop a high degree of phonological awareness (e.g., in highly regular languages such as German and Italian), they have problems learning to recognize words fluently (Paulesu, et al., 2001; Wimmer, 1993; Wimmer, Mayringer, \& Landerl, 2000). Owing to their basic word reading or decoding problems, they may have failed to reach a more fluent level of development due, in part, to general difficulties in mastering implicit or probabilistic rule systems.

Scientists endeavoring to uncover the cognitive and neural bases of dyslexia have questioned whether learning to read shares common features with nonlinguistic types of learning. In two recent studies, researchers explored implicit learning deficits in dyslexia and hypothesized how such deficits share in the etiology of dyslexia (Kelly, Griffiths, \& Frith, 2002; Vicari, Marotta, Menghini, Molinari, \& Petrosini, 2003). Vicari et al. (2003) compared the implicit and explicit abilities of individuals with and without dyslexia using a serial reaction time task, which required participants to learn to predict a temporal sequence quickly and accurately. Such serial reaction time tasks have frequently been used to study implicit learning ability in various patient populations (e.g., Exner, Koschack, \& Irle, 2002; Nissen \& Bullemer, 1987). The participants with dyslexia in Vicari et al.'s study had longer reaction times in the implicit task, but performed the same as those without dyslexia in the explicit task. Using a similar type of task, Kelly et al. (2002) found that participants with dyslexia had longer reaction times and made more errors on implicit tasks, but their group learning rate was parallel to that of their peers. Vicari et al., and Kelly et al. to a lesser extent, credit the cerebellum as the neural site of implicit learning in serial reaction time tasks, and take their findings as evidence either for (Vicari, et al., 2003) or against (Kelly, et al., 2002) the possibility that dyslexia may be due, in part, to a deficit in the supposed automatization function of the cerebellum, as others have suggested (Nicolson, Fawcett, \& Dean, 2001). While there is no doubt that the cerebellum contributes to learning, tying implicit learning solely to the cerebellum may be an oversimplification of the actual neural mechanisms involved, particularly given the extensive neu- 
ropsychology literature that links impairments on implicit learning tasks to lesions within specific brain regions, covering a much wider range of brain regions than just the cerebellum (Keri, 2003; Knowlton \& Squire, 1993; Maddox \& Filoteo, 2001).

In our study, rather than use a serial reaction time task as in the two previous studies of explicit and implicit learning in dyslexia (Kelly, et al., 2002; Vicari, et al., 2003), we devised explicit and implicit categorical learning tasks. We based our tasks on the ones that had been used extensively in the categorical learning literature to investigate explicit and implicit learning (Ashby \& Ell, 2001; Ashby \& Maddox, 1993; Keri, 2003; Knowlton \& Squire, 1993; Maddox \& Filoteo, 2001; Medin \& Schaffer, 1978; Nosofsky, 1986), particularly as it relates to Parkinson's disease, medial temporal lobe amnesia, and Alzheimer's disease. Ashby and Maddox (1993) constructed tasks in which the category rule was either easily explicated or difficult to explain, and were able to show that participants could learn both rule types to similar levels of proficiency. Learning was inferred to be implicit when the rule could not be explained. Parksinson's patients, who typically have impaired procedural learning, had particular difficulty with this kind of implicit task (Ashby, et al., 1998; Knowlton, Mangels, \& Squire, 1996; Maddox \& Filoteo, 2001).

Ashby \& Maddox's (1993) design could enable us to theorize more broadly about neural bases for performance differences. Moreover, the explicit and implicit tasks were structured in a highly comparable manner, involving similar kinds of simple geometric figures to be categorized, making the results readily interpretable. To address theoretically important issues of phonological and orthographic processing, we gave participants a set of reading and cognitive tests to see if performance on the explicit and implicit learning tasks correlated with particular aspects of reading performance. If poor reading in adulthood stems, in part, from difficulties in implicit or probabilistic learning, we can predict that adults having problems with basic reading skills have experienced difficulty reaching the implicit stage of learning about orthography and orthography-phonology correspondences, and that their performance on tests of phonology and orthography may be correlated with the accuracy and rate of their implicit categorical learning. In addition, if implicit learning is more crucial to attaining adult levels of reading fluency and proficiency than explicit learning, we might expect that, in adults, reading skill will be correlated primarily with performance on the task requiring implicit learning. 


\section{METHOD}

\section{PARTICIPANTS}

Fifty-four participants were recruited for the study. All were students at the University of Southern California. Forty-five of the participants were recruited from undergraduate psychology classes. Advertisements for these students specified fluency in English, and either normal reading abilities or a history of reading problems. Five of the participants in the poor reader group and four of the participants in the good reader group were recruited through ads placed in the campus newspaper requesting the identical requirements to those used to recruit the psychology students. Psychology students received credit for their participation; all others received payment for their participation. All testing was done in a dedicated testing room at the University of Southern California. Informed consent was obtained from all participants.

\section{READING TESTS}

In order to evaluate reading ability, we administered both standardized and nonstandardized tests.

Woodcock Johnson Tests of Achievement-III (as described in Mather $\mathcal{E}$ Woodcock, 2001a).

Letter-Word Identification: This task assessed word reading skill (median reliability $=.94$ ).

Word Attack: This task assessed phonological decoding through nonsense word reading (median reliability $=.87$ ).

\section{ORTHOGRAPHIC SKILL}

Exception Word Reading. This task required participants to pronounce 70 items along a gradient of increasing complexity and decreasing frequency: e.g., ocean ... cognac.

Orthographic Choice. This task required participants to decide which of two printed stimuli, a word or a pseudohomophone (e.g., rain versus rane, seperate versus separate) was a correctly spelled word (60 trials) (adapted from Olson, Wise, Conners, Rack, \& Fulker, 1989). Participants were instructed to respond as quickly as possible without making mistakes, and responses were recorded via a button box.

\section{COGNITIVE ABILITY TESTS}

Nonverbal and verbal cognitive processing were evaluated with two tests. Though limited, the cognitive assessment served the 
purpose of making sure individuals were within the normal range for nonverbal and verbal ability.

Woodcock Johnson Tests of Cognitive Abilities-III (as described in Mather \& Woodcock, 2001b):

Spatial Relations: This task assessed visual-spatial thinking, and the ability to perceive and manipulate visuallypresented patterns. Participants identified two or three pieces that together formed a target shape. Successive test items increased in difficulty by involving flipped or rotated pieces and increasingly similar foils (median reliability $=.85$ ).

Verbal Comprehension: This test included four subtestsPicture Vocabulary, Synonyms, Antonyms, and Verbal Analogies-measuring lexical knowledge, vocabulary, and language development (median reliability $=.95$ ).

All participants were queried as to whether they had a childhood history of reading problems in order to help us better determine whether any of the participants could be classified as having dyslexia, although this information was not used as a criterion for inclusion or exclusion in either group. In order to be classified for the poor reader group, participants had to score below the 25th percentile on Word Attack and to score within a standard deviation of the national mean (standard score of 85 or higher) on both the Spatial Relations and Verbal Comprehension measures. Although some studies use word identification measures as the sole criterion for defining reading problems and/or dyslexia in adults, we used nonword pronunciation because adult poor readers who enter a university may be a biased sample, likely the most capable of compensating. Compensated adults with dyslexia may not reach equivalent levels of word identification skill to adults without dyslexia; however, they clearly show far greater improvement in word identification than in nonword reading (Bruck, 1990; Pennington \& Lefly, 2001). Good readers needed to score above the 40th percentile on both Word Identification and Word Attack, and attain a scaled score of at least 85 on both the cognitive ability tests. A total of 24 participants qualified for the poor reader group (5 males and 19 females; 11 white, 2 Hispanic, 6 black, 5 Asian), fifteen of whom reported a history of reading difficulties, and another five of whom reported having been diagnosed at some point as having dyslexia or dyslexia-like reading problems. Thirty participants qualified for the good reader group (11 males and 19 females; 14 white, 5 Hispanic, 2 black, 9 Asian), one of whom reported being a slow reader. 


\section{CATEGORICAL LEARNING TASKS}

To create stimulus sets for each of the categorical learning tasks, we broadly followed the guidelines for explicit and implicit test stimuli described by Ashby and Ell (2001). Both tasks were instances of few-exemplar categorical structure. Stimuli consisted of a combination of some of the following possibilities: small black or white geometric shapes (square, rectangle, or circle) superimposed on a larger colored geometric shape, appearing in the center of a white computer screen. For each task, participants were instructed to sort the composite shapes into two groups by pressing either the left or right button. Participants were encouraged to press the buttons arbitrarily at the beginning of each task, and were told that auditory feedback would signal correct choices to help them learn. At the end of each task, participants were asked what they thought the sorting rule had been, and these verbal responses were transcribed. Speed of button presses was not recorded.

Explicit Learning Task. Stimuli consisted of four binary features for a total of 16 exemplars, eight in each category. The four binary dimensions in the task were background color (turquoise or purple), inside color (black or white), inside shape (square or circle), and inside size (big or small). Correct categorization of the shapes was based on one of the four (inside size), while the other three dimensions were irrelevant. Thus the rule was straightforward and easily verbalized: "For big shapes press the left button (A); for small shapes press the right button (B)." Figure 1a depicts the types of exemplars and category structure in the explicit task (using shading in place of background color).

Implicit Learning Task. Stimuli consisted of two binary features and one quaternary feature for a total of 16 exemplars, eight in each category. The two binary dimensions were inside shape (square or rectangle) and inside color (black or white). The quaternary dimension was background color (red, blue, green, gray). Structure was built around a combination of one of the binary features (inside color) with the quaternary feature. The inside shape was the irrelevant feature. The rule was difficult to verbalize: "For all reds, regardless of other features, plus all blue-whites and green-whites, press the left button (A); for all grays, regardless of other features, and all blue-blacks and green-blacks, press the right button (B)." Figure $1 \mathrm{~b}$ depicts the structure of the implicit task, with shading in place of background color. 

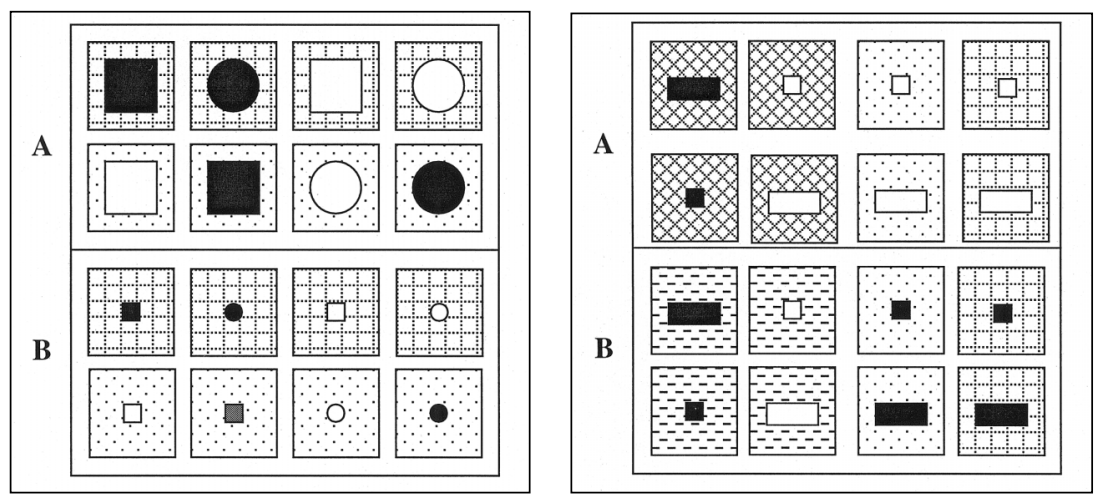

Figure 1(a-b). These figures exhibit the types of simple geometric shapes in the categorical learning tasks. In the explicit task (a, above left), there are four binary features (background shading, inside shape, inside color, inside size). Only one feature is relevant for the sorting rule (inside size). Category $A$ is composed only of items with large inside shapes, regardless of other features, while Category B is composed only of items with small inside shapes, regardless of other features. In the implicit task (b, above right), there are two binary features (inside shape and inside color, the latter being irrelevant) and one quaternary feature (background shading). The rule involves a combination of the two relevant feature types and is thus more difficult to articulate.

\section{PROCEDURES}

The experiment was programmed using Matlab 5.2 with Psychtoolbox extensions (Brainard, 1997), and run on a Macintosh G4 with an Apple Multiple Scan 720 monitor. Each task followed the same procedure. For a maximum of 200 trials, participants were shown a series of exemplars and had to decide in which category the exemplar belonged. Reponses were recorded via keyboard or button box. A computer "beep" indicated correct responses. At the end of each task, participants were asked what they thought the rule was, and their responses were recorded. Each participant received a unique, random sequence of exemplars. Order of tasks was counterbalanced across participants.

The criterion level of performance in categorical learning tasks is arbitrary. As there were no data in the literature on the performance of poor readers on our tasks, we adopted a conservative approach. We had determined, based on pilot data from 
similar categorical learning tasks, that those participants whose performance still hovered around 50\% correct after 200 trials made minimal progress with additional trials because they became frustrated and bored. The first 23 participants were given the implicit task only to make certain the rule could be learned; then administration of the explicit task was added. These initial participants all received 200 trials. However, several individuals learned the implicit rule fairly early (i.e., they began getting every trial correct) and became bored as further trials were given. To avoid giving pointless trials, the remaining 31 participants were allowed to stop, on both implicit and explicit tasks, when they had attained cumulatively eight blocks of trials with at least eight out of 10 responses correct. If they did not meet this criterion, they received a maximum of 200 trials. The change resulted in far fewer than 200 trials being given to most of the remaining participants. Analyses showed that reading and cognitive scores (Word Identification, Word Attack, Verbal Comprehension, or Spatial Relations) of the whole sample of good and poor readers were not significantly different from the subsample who were given both tasks.

For scoring purposes, we adopted a less stringent criterion of three consecutive blocks of eight out of 10 correct responses, as this criterion was almost always achieved well before a participant attained the eight blocks, and was thus an impartial metric that allowed us to collapse across participants. The fact that some of the participants had more trials than others is thus irrelevant to the score. Two scores were obtained. The first was the number of trials to criterion. The second score was the percent correct for all trials up to and including the third consecutive block. All participants met criterion for the explicit task (maximum trials to criterion was 115). On the implicit task, one poor reader and six good readers failed to reach criterion within the 200 trials, although these participants had reading and cognitive scores close to the means of their respective reading groups. All seven were among those who performed the explicit task.

\section{RESULTS}

\section{READING AND COGNITIVE TEST SCORES}

Table I provides the reading and cognitive test scores for the full sample. The reading and cognitive scores of the subset of participants who performed the explicit task were equivalent to those of the full sample in terms of the key variables of Word 
Identification, Word Attack, Verbal Comprehension, and Spatial Relations. Exception Word scores represent the mean number of correctly pronounced words out of 70 . Because Orthographic Choice was a forced choice task, scores were converted to $d^{\prime}$ values according to Signal Detection Theory (Green \& Swets, 1966). Correctly choosing the word when it appeared on the left side of the computer screen was considered a "hit" whereas incorrectly choosing the pseudo-homophone when it appeared on the left side of the screen was considered a "false alarm." The $d$ ' values were calculated according to the following formula:

$$
d^{\prime}=\text { Z-score(hits) - Z-score(false alarms) }
$$

Response latency was not correlated with accuracy $(p>$ 0.10). Poor readers had significantly lower scores than good readers in Word Identification, Word Attack, Orthographic Choice, and Exception Word Reading. As expected, given their status as university-level students, the poor readers' Word Identification scores, although below the national norm group mean, were not as low as their Word Attack scores. The combination of slightly below average word reading and well below average nonsense word reading fits the dyslexic adult profile described by Bruck (1990), Pennington and Lefly (2001), and others. Furthermore, more than half of the individuals in the poor reader group had a history of reading problems, which had clearly not been fully ameliorated by adulthood. Thus, we could possibly redefine the poor reader group as a dyslexia group. However, we prefer to use the phrase "poor readers" or perhaps "poor decoders" as this is more descriptive in this instance. All participants met our Verbal Ability and VisualSpatial Ability criteria; however, poor readers had significantly lower scores than good readers on Verbal Comprehension $(t(53)=2.75, p<.01)$ and Spatial Relations $(t(53)=2.80, p<.01)$. The difference in Verbal Comprehension was not surprising because reading experience is closely tied to verbal development, and the degree to which Verbal ability can be considered independent from reading experience has been repeatedly called into question (e.g., Gottardo, Stanovich, \& Siegel, 1996; Share, 1995; Stanovich, 1986; Stanovich \& Siegel, 1994). The group difference on Spatial Relations, on the other hand, was not expected, although the poor reader group mean was higher than the mean for the national norm group. Given these group differences, we were careful to co-vary out these cognitive measures in group comparisons and regression analyses as described in the table on the next page. 
TABLE I. Reading and Cognitive Scores (Means and SD).

\begin{tabular}{|c|c|c|c|}
\hline & $\begin{array}{l}\text { Good Readers } \\
\quad N=30\end{array}$ & $\begin{array}{c}\text { Poor Readers } \\
N=24\end{array}$ & $t$-value \\
\hline Age years; months) & $21.5(3.3)$ & $20.7(1.7)$ & 1.23 \\
\hline \multicolumn{4}{|c|}{ WJ-III Tests of Achievement-Standard Scores } \\
\hline Letter-Word ID & $108(7.4)^{\mathrm{b}}$ & $95(6.7)$ & 7.20 \\
\hline Word Attack & $102(6.2)^{b}$ & $84(4.2)$ & 13.53 \\
\hline \multicolumn{4}{|c|}{ WJ-III Tests of Cognitive Abilities_Standard Scores } \\
\hline Verbal Comprehension & $104(9.7)^{a}$ & $98(7.5)$ & 3.23 \\
\hline Spatial Relations & $109(10.6) \mathrm{a}$ & $102(9.1)$ & 3.04 \\
\hline Exception Words (/70) & $63(2.7)^{b}$ & $57(3.6)$ & 7.80 \\
\hline Orthographic Choice $\left(d^{\prime}\right)$ & ') $2.8(0.5)^{\mathrm{b}}$ & $2.3(0.5)$ & 3.42 \\
\hline
\end{tabular}

$\mathrm{a} p<.01 ; \mathrm{b} p<.001$

\section{CATEGORICAL LEARNING TASKS}

Table II shows the mean number of trials to criterion and mean percent correct for both tasks, as well as the number of participants in each group for each task. For both tasks, the data reflect the participants who performed the task to criterion (all 31 for the explicit task and 47 for the implicit task). In the case of the trials-to-criterion scores, lower scores indicate faster learning. Preliminary analyses revealed no significant effect for order on either task $(p>.25)$, so we collapsed across order. On the explicit task, poor readers and good readers did not differ significantly in rate of rule learning or overall accuracy. Everyone could correctly state the rule, except for one poor reader who included references to an irrelevant feature. In contrast, although some participants could articulate parts of the implicit rule, none could correctly state it in its entirety, supporting the assumption that the task involved implicit learning. For example, several participants mentioned the red/gray distinction, but then said they guessed about blues and greens. Other participants claimed to have sorted according to whether the inner shape was black or white "in general," which was a valid strategy, yet they also ascribed significance to the inner shape, which was, in fact, irrelevant. A few claimed to have "memorized the colors and shapes," but could provide no further details when queried, and a handful suggested that it was entirely based on the pattern of button presses.

Poor readers learned more slowly than good readers on the implicit task, requiring, on average, 32 more trials to reach crite- 
rion, $t(45)=2.57, p<.02$. The group difference remained significant when either Verbal Comprehension scores were held constant, $F(1,44)=4.40, p<.05$ or Spatial Relations scores were held constant, $F(1,44)=7.10, p<.05$. The group difference in mean percent correct across learning trials was significant, $t$ (45) $=3.75, p<.001$, and also remained significant when both Verbal Comprehension scores and Spatial Relations scores were held constant, $F(1,44)=11.45, p<.01$. In order to determine the impact, if any, of the performance of the seven participants who failed to reach criterion on the implicit task on the overall group difference, percent correct scores were calculated based on their overall performance (200 trials) and their data were added to those of the group that reached criterion. The difference in mean percent correct remained significant, $t(52)=2.22, p<.05$. When the groups were restricted to include only those participants who had the opportunity to perform both tasks (good readers $=13$, poor readers $=11$ ), allowing a matched comparison of tasks, the difference in mean percent correct remained, although it was marginal, $t(23)=2.04, p=.053$. Due to the large variability in trials-to-criterion within the smaller restricted sample, although poor readers did require, on average, 13 more trials to reach criterion than good readers, this difference did not reach significance. Within-subjects analyses revealed that the mean for trials to criterion was lower for the explicit task than for the implicit task $(t(23)=4.85, p<.001)$, consistent with faster explicit categorical learning.

TABLE II. Categorical Learning Performance (Means and SD).

\begin{tabular}{|c|c|c|c|c|c|}
\hline & Good readers & Poor readers & $t$-value & $p$-value & \\
\hline \multicolumn{6}{|l|}{ Explicit task } \\
\hline $\begin{array}{l}\text { Trials to } \\
\text { criterion }\end{array}$ & $53(23)$ & $44(25)$ & .98 & n.s. & \\
\hline Min/Max & $30 / 101$ & $30 / 115$ & & & \\
\hline$\%$ correct & $80(9.8)$ & $82(8.8)$ & -.45 & n.s. & \\
\hline$N$ & 19 & 12 & & & \\
\hline Implicit task & & & & \multicolumn{2}{|c|}{ Effect size $(d)$} \\
\hline $\begin{array}{l}\text { Trials to } \\
\text { criterion }\end{array}$ & $73(40)$ & $105(46)$ & 2.57 & $<.02$ & .79 \\
\hline Min/Max & $30 / 164$ & $33 / 199$ & & & \\
\hline$\%$ correct & 75 (7.3) & $67(6.6)$ & 3.75 & $<.001$ & 1.03 \\
\hline$N$ & 24 & 23 & & & \\
\hline
\end{tabular}


Performance on the implicit task was correlated with several of the reading and cognitive test scores but explicit task performance was not (see table III). It is apparent from table II that this was not due to a dramatically more restricted range of scores on the explicit than the implicit task, particularly for percent correct scores. Trials to criterion was correlated with Word Identification, $r(47)=-.29, p<.05$. Percent correct was correlated with Word Identification, $r(47)=.39, p<.01$, Word Attack, $r(47)=.36, p<.01$, Verbal Comprehension, $r(47)=.43, p<.01$, and Exception Word Reading scores, $r(47)=.33, p<.01$. The correlation between percent correct and Orthographic Choice score did not reach significance, $r(47)=.13, p>.25$. Percent correct was not correlated significantly with Spatial Relations.

A series of hierarchical regression analyses was conducted to determine whether implicit task performance (percent correct) accounted for unique variance on the individual reading

TABLE III. Correlations between Categorical Learning Tasks and Reading/Cognitive Tasks.

\begin{tabular}{|c|c|c|c|c|c|c|c|c|c|}
\hline & \multicolumn{3}{|c|}{ Categorical Learning } & \multicolumn{2}{|c|}{$\begin{array}{c}\text { WJ-III } \\
\text { Achievement } \\
\text { Tests } \\
\end{array}$} & \multicolumn{2}{|c|}{$\begin{array}{c}\text { WJ-III } \\
\text { Cognitive } \\
\text { Tests } \\
\end{array}$} & \multicolumn{2}{|c|}{$\begin{array}{c}\text { Additional } \\
\text { Tests }\end{array}$} \\
\hline & E_Trial E\% & I_Trial & $\mathbf{I} \%$ & LWID & WA & Verbal & Spatial & Orth_Choice & Except \\
\hline \multicolumn{10}{|l|}{ E_Trial } \\
\hline $\mathrm{E} \%$ & $-.72 \mathrm{~b}$ & & & & & & & & \\
\hline I_Trial & $.30-.32$ & & & & & & & & \\
\hline $\mathrm{I} \%$ & $-.22-.003$ & $-.58 \mathrm{~b}$ & & & & & & & \\
\hline LWID & $.16 \quad .12$ & $-.29 a$ & $.39 \mathrm{~b}$ & & & & & & \\
\hline WA & $.3-.12$ & -.26 & $.36^{\mathrm{b}}$ & $.67 \mathrm{~b}$ & & & & & \\
\hline Verbal & $1.18-.16$ & -.22 & $.43^{b}$ & $.61^{b}$ & $.39 a$ & & & & \\
\hline Spatial & $1.17-.15$ & -.068 & .037 & $.42^{\mathrm{a}}$ & $.56^{b}$ & .20 & & & \\
\hline \multicolumn{10}{|l|}{ Orth_ } \\
\hline Choice & .036 & -.16 & .13 & $.54 \mathrm{~b}$ & $.42^{b}$ & .28 & .14 & & \\
\hline Except & t. $.25-.22$ & -.26 & $.33^{b}$ & $.83^{b}$ & $.68^{\mathrm{b}}$ & $.54^{\mathrm{b}}$ & $.43^{b}$ & $.46^{\mathrm{b}}$ & - \\
\hline
\end{tabular}

Abbreviations: E_Trial: Explicit task trials to criterion; E\%: Explicit task percent correct; I_Trial: Implicit task trials to criterion; I\%: Implicit task percent correct; LWID: Letter-Word Identification; WA: Word Attack; Verbal: Verbal Comprehension; Spatial: Spatial Relations; Orth_Choice: Orthographic Choice; Except: Exception word reading. $N$ for Explicit task $=21 ; N$ for Implicit task and all correlations between reading and cognitive scores $=47$. 
tasks, Word Identification, Word Attack, and Exception Word Reading, controlling for the cognitive measures. For these analyses, percent correct scores were trimmed to exclude those within 1.5 standard deviations of chance (50\% correct). Given the group difference on Verbal Comprehension, these scores were entered first and accounted for $35.1 \%$ of the variance in Word Identification, $t(41)=4.70, p<.001$. Although not correlated with implicit learning scores, in consideration of the group difference, we next entered Spatial Relations scores, which contributed an additional $5.2 \%$ variance, although this was marginal, $t(40)=1.87, p=.07$. Implicit learning accounted for an additional $8.2 \%$ unique variance, $t(39)=2.51, p<.02$. For Word Attack, the figures were $10.5 \%$ for Verbal Comprehension, $t(41)=2.19, p<.05,18.2 \%$ for Spatial Relations, $t(40)=3.20, p<$ .01 , and $12.8 \%$ for implicit learning, $t(39)=2.91, p<.01$. For Exception Word Reading, Verbal Comprehension accounted for $29.7 \%, t(41)=4.16, p<.001$, Spatial Relations accounted for $6.6 \%$, $t(40)=2.05, p<.05$, and implicit learning an additional $4.3 \%$, although this was not significant, $t(39)=1.67, p=.10$. With Spatial Relations removed from the regression model for exception words, implicit learning accounted for $6.3 \%$ of the variance independent of Verbal Comprehension, $t(40)=1.99, p=.05$. Thus categorical learning, which requires substantial integration of information, thereby involving implicit learning, would appear to gauge aspects of reading ability independent of certain cognitive abilities.

\section{DISCUSSION}

The primary goal of the study was to investigate the relationship between reading and explicit and implicit categorical learning, utilizing samples of adult good and poor readers. Both learning tasks involved categorizing simple geometric shapes. Given the similar task designs, rather than assuming the two tasks assess separate mental operations, it is possible to view them as existing on a continuum in terms of the degree of integration of information required. The explicit task entailed category boundaries defined by a single, wholly consistent feature, requiring the least integration of information. The implicit task entailed category boundaries that involved the blending of features such that features could not be classified consistently out of context, thereby requiring greater integration of information. While the learning rule for the explicit task could be easily 
articulated, post-experiment debriefing found that none of the participants could explain the rule for the implicit task. Yet the great majority of participants could perform the implicit task well above chance. As a result, although they may exist on a continuum, the two tasks did meet the basic criteria for the labels "explicit" and "implicit" as described in the memory and learning literature (Ashby \& Ell, 2001).

It is important to understand how impairments in implicit learning relate to poor readers' reading profiles. While the explicit task is entirely consistent, centered on $a$ single relevant feature, in order to solve the implicit tasks, participants must identify and integrate the multiple relevant features in the display, despite the apparent inconsistencies, and ignore the irrelevant features. The process invoked in solving the latter task may have a parallel in learning to read. In order to establish solid yet flexible mental representations, beginning readers must learn to identify essential aspects of phonemes and how they relate to orthographic patterns (Booth, Perfetti, \& MacWhinney, 1999; Harm \& Seidenberg, 1999). For example, when learning letter names and how to blend phonemes, successful learners must notice that the /s/ in SING and the /s/ in THIS are the same phoneme, despite the fact that they appear in different contexts and are pronounced somewhat differently. An inability to ignore irrelevant differences between exemplars of phonemes could have a decidedly negative impact on the learning process. The differences are not relevant to the fact that both are instances of a common category, the phoneme /s/. As a result, an individual's ability to both form and manipulate appropriate perceptual categories would be compromised. Thus poor implicit cognition would hinder phonological representation and processing, as well as learning and automatization of orthographic-phonological representations.

Potential evidence of a connection between the ability to ignore irrelevant differences and poor reading comes from several sources. Serniclaes, Sprenger-Charolles, Carré, and Démonet (2001) found that when asked to discriminate exemplars along a place-of-articulation (POA) continuum $(b a-d a)$, children with dyslexia were more sensitive than children without dyslexia to slight differences between sounds within the same category. Resultant discrimination curves were less peaked, suggesting the dyslexic children had weaker phoneme boundaries. The results echoed earlier trends found in data from Godfrey, SyrdalLasky, Millay, and Knox (1981) and Werker and Tees (1987) that children with dyslexia had better within-category discrimina- 
tion than children without dyslexia but poorer betweencategory discrimination. Manis and Keating (in press) reported similar results in a task in which participants decided whether stimuli along a spy-sky place of articulation continuum were the same or different. Dyslexic children with oral language impairments on grammatical and semantic tasks (LI) had better within-category discrimination than other dyslexic children and normally reading children but poorer between-category discrimination. In short, dyslexics with LI perceived what the others had learned to ignore. In the present context, the relationship of implicit learning to word and nonword reading accuracy might, therefore, be based, in part, on the relationship of implicit learning to perceptual categorization at the phonemic level.

Moving outside the domain of phonology and reading, are implicit learning deficits relevant to other empirically established cognitive difficulties association with poor reading and dyslexia? In a series of studies (Manis, Sperling, \& Lu, 2004; Sperling, 2004; Sperling, Lu, \& Manis, 2003), we found that poor readers had deficits in motion perception and luminance contrast sensitivity only when they were required to extract the motion or luminance signal from highly noisy displays. They performed as well as good readers when noise was reduced, even at very low signal (coherence/contrast) levels. We view the findings as indicative of a potential deficit in distractor (or irrelevance) exclusion rather than in motion perception per se, as has been previously suggested (for example, Eden, et al., 1996; Talcott, Hansen, Assoku, \& Stein, 2000). Thus, there is both visual and auditory evidence to support the hypothesis that individuals with reading problems or dyslexia may have degrees of difficulty ignoring irrelevant features in certain visual and auditory tasks.

The hypothesis also gains support from studies of executive functioning. Brosnan et al. (2002) investigated whether individuals with dyslexia had difficulty inhibiting responses to distractors. They compared dyslexic adults' and nondyslexic adults' performance on a well-validated test of executive functioning, the Group-embedded figures test (GEFT) (Witkin, Oltman, Raskin, \& Karps, 1971). Successful performance on the test requires that an individual identifies a shape while ignoring confusing distractors. The dyslexic adults were much worse on the task than nondyslexic adults. An obvious question is, What brain regions are related to the task? In light of the applied neuropsychology literature on the GEFT, Brosnan, et al. linked poor 
GEFT performance to impaired prefrontal (executive) function and suggested that individuals with dyslexia may have impaired executive cognition. There is evidence that individuals with dyslexia who also have ADHD have executive functioning deficits (Willcutt, et al., 2001). Highly co-morbid with dyslexia, ADHD is known to involve executive function deficits (Barkley, 1997). As an alternative hypothesis, implicit learning deficits could underlie poor GEFT performance. Brain regions other than the prefrontal cortex could contribute to dyslexic adults' functioning on both GEFT and implicit learning tasks, and in all likelihood, a subtle interplay exists.

The relationship of implicit learning to other aspects of reading in the present study, such as orthographic skill, is more difficult to explain than the relation to phonological skill and nonword decoding. While there was a significant correlation of implicit learning with Exception Word Reading, considered to be a measure of orthographic knowledge, the correlation with Orthographic Choice, an arguably more direct measure of orthographic knowledge, was not significant. The discrepancy could be due to the fact that finding items for the Orthographic Choice test that challenge adults is difficult because the number of potential items is rather limited. Experimenters must create foils that are difficult enough that participants cannot easily reject the foil based on partial knowledge of the correct spelling (e.g., FASCINATE is chosen over its foil FASSINATE because the reader knows there is a ' $c$ ' somewhere in the word). In fact, a number of participants performed at ceiling levels of accuracy on Orthographic Choice. A second aspect of the discrepancy relates to the fact that Exception Word Reading does involve phonological decoding as well as orthographic skill, and as such, the correlation could be due more to the former than the latter, although the orthographic component should not be entirely dismissed.

At the adult level of reading achievement, reading words and nonwords, whether familiar or uncommon, may involve mostly implicit strategies. Although reading novel words (such as those on the Work Attack test) may involve some explicit application of spelling-sound rules, the harder items-meant to challenge adults-involve orthographic clusters that may not have been explicitly learned. For example, one of the final items, PHIGH (rhymes with lie), requires that participants generalize from the small family of words with the -igh spelling pattern. Rather than apply a rule for the nonword phigh, readers may make implicit associations with other similar appearing 
words in their memory such as sigh, high, phone, etc. (after the manner of a connectionist model such as Harm \& Seidenberg, 1999). If, as suggested previously, learning to read involves overlapping processes of explicit and implicit learning, then we might expect that the relationships between types of categorical learning and reading skills would be somewhat different in children than adults. For example, explicit rule learning may be more strongly related to word decoding and recognition in children than in adults.

In recent reviews, both Ashby and Ell (2001) and Keri (2003) have suggested the mechanisms involved in both explicit and implicit categorical learning differ, depending on the stimulus type. Patients with either frontal or medial temporal lobe lesions were impaired on explicit categorical tasks requiring easily articulated rules, whereas patients with basal ganglia lesions had inconsistent performance, although it should be noted that in the case of medial temporal lobe amnesia, several contradictory findings have been reported (Keri, 2003). On implicit tasks with many exemplars, only basal ganglia patients were impaired, while on implicit tasks with few exemplars, as in the current study, frontal lobe patients were normal, medial temporal lobe amnesiacs were normal at first but performance degrades over time, and basal ganglia patients were impaired (Ashby \& Ell, 2001). Thus task structure, as well as location of lesion (and most likely extent of damage), can influence whether deficits are found.

A number of studies have shown that patients with basal ganglia lesions were impaired on the kind of implicit categorical learning task our poor readers had trouble with here (Maddox \& Filoteo 2001; Knowlton, Mangels, \& Squire, 1996; Knowlton, et al., 1996; Ashby, et al., 1998). We admit it would be premature to speculate from poor implicit categorical learning that adult poor readers necessarily have basal ganglia impairments. However, disruption in basal ganglia function could be a piece in the larger puzzle that is developmental dyslexia, and could help explain some of the perceptual-motor deficits sometimes found to be associated with dyslexia such as lack of automatization in performance of choice reaction time tasks (Nicolson, et al., 2001), and impairment in tapping out the beat of a metronome (Wolff, Michel, Ovrut, \& Drake, 1990).

Regardless of the particular brain regions involved, we conclude that implicit categorical learning is related to reading ability, and that it is deficient in adult poor readers, while explicit categorical learning is normal. Not only did poor readers take 
longer to learn the implicit rule, and with lower overall accuracy, but also the performance of the entire sample on the implicit learning task was related to three different word reading and phonological decoding tasks. For each reading task, implicit learning skill accounted for variance independent of verbal comprehension scores.

\section{ACKNOWLEDGEMENTS}

This research was supported by NICHD grant HD29891 (P.I.: F.R. Manis). We thank Brad Hubisz for help in running the participants.

Address correspondence to: Anne Sperling, 4000 Reservoir Road NW, Building D, Room 207E, Georgetown University, Washington, DC 20057. Tel-202-687-1767, Fax-202-784-3504, E-mail-annejessica@yahoo.com; Zhong-Lin Lu, E-mailzhonglin@usc.edu, tel-213-740-2282, fax-213-746-9082; or Franklin R. Manis, E-mail— manis@ usc.edu, tel-213-740-6567, fax-213-746-9082.

\section{References}

Ashby, F. G., Alfonso-Reese, L. A., Turken, U., \& Waldron, E. M. (1998). A neuropsychological theory of multiple systems in category learning. Psychological Review, $105,442-481$.

Ashby, F. G., \& Ell, S. W. (2001). The neurobiology of human category learning. Trends in Cognitive Science, 5, 204-210.

Ashby, F. G., \& Maddox, W. T. (1993). Relations between prototype, exemplar, and decision bound models of categorization. Journal of Mathematical Psychology, 37, 372-400.

Barkley, R. A. (1997). Behavioral inhibition, sustained attention, and executive functions: Constructing a unifying theory of ADHD. Psychological Bulletin, 121, 65-94.

Booth, J. R., Perfetti, C. A., \& MacWhinney, B. (1999). Quick, automatic, and general activation of orthographic and phonological representations in young readers. Developmental Psychology, 35, 3-19.

Brainard, D. H. (1997). The psychophysics toolbox. Spatial Vision, 10, 433-436.

Brosnan, M., Demetre, J., Hamill, S., Robson, K., Shepherd, H., \& Cody, G. (2002). Executive functioning in adults and children with developmental dyslexia. Neuropsychologia, 40, 2144-2155.

Bruck, M. (1990). Word-recognition skills of adults with childhood diagnoses of dyslexia. Developmental Psychology, 26, 439-454.

Coltheart, M., Curtis, B., Atkins, P., \& Haller, M. (1993). Models of reading aloud: Dualroute and parallel-distributed processing approaches. Psychological Review, 100, 589-608. 
Eden, G. F., Vanmeter, J., Rumsey, J., Maisog, J., Woods, R., \& Zeffiro, T. (1996). Abnormal processing of visual motion in dyslexia revealed by functional brain imaging. Nature, 382, 66-69.

Ehri, L. C. (1990). Development of the ability to read words. In R. Barr, M. L. Kamil, P. B. Mosenthal, \& P. D. Pearson (Eds.), Handbook of reading research (vol. 2, pp. 383-417). New York: Longman.

Ehri, L. C., Nunes, S. R., Stahl, S. A., \& Willows, D. M. (2001). Systematic phonics instruction helps students learn to read: Evidence from the National Reading Panel's meta-analysis. Review of Educational Research, 71, 393-447.

Exner, C., Koschack, J., \& Irle, E. (2002). The differential role of premotor frontal cortex and basal ganglia in motor sequence learning: Evidence from focal basal ganglia lesions. Learning and Memory, 9, 376-386.

Godfrey, J., Syrdal-Lasky, A., Millay, K., \& Knox, C. (1981). Performance of dyslexic children on speech perception tests. Journal of Experimental Child Psychology, 32, 401-424.

Gottardo, A., Stanovich, K. E., \& Siegel, L. S. (1996). The relationships between phonological sensitivity, syntactic processing, and verbal working memory in the reading performance of third-grade children. Journal of Experimental Child Psychology, $63,563-582$.

Green, D. M., \& Swets, J. A. (1966). Signal detection theory and psychophysics. New York: Wiley.

Harm, M., \& Seidenberg, M. S. (1999). Phonology, reading acquisition, and dyslexia: Insights from connectionist models. Psychological Review, 106, 491-528.

Harm, M., \& Seidenberg, M. S. (2004). Computing the meanings of words in reading: Cooperative division of labor between visual and phonological processes. Psychological Review, 111, 662-720.

Karmiloff-Smith, A. (1992). Beyond modularity: A developmental perspective on cognitive science. Cambridge, MA: MIT Press.

Kelly, S. W., Griffiths, S., \& Frith, U. (2002). Evidence for implicit sequence learning in dyslexia. Dyslexia, 8, 43-52.

Keri, S. (2003). The cognitive neuroscience of category learning. Brain Research Reviews, $43,85-109$.

Knowlton, B. J., Mangels, J. A., \& Squire, L. R. (1996). A neostriatal habit learning system in humans. Science, 273, 1399-1402.

Knowlton, B. J., \& Squire, L. R. (1993). The learning of categories: Parallel brain systems for item memory and category knowledge. Science, 262, 1747-1749.

Knowlton, B. J., Squire, L. R., Paulsen, J. S., Swerdlow, N. R., Swenson, M., \& Butters, N. (1996). Dissociations within nondeclarative memory in Huntington's disease. Neuropsychology, 10, 538-548.

Maddox, W. T., \& Filoteo, J. V. (2001). Striatal contributions to category learning: Quantitative modeling of simple linear and complex non-linear rule learning in patients with Parkinson's disease. Journal of the International Neuropsychological Society, 7, 710-727.

Manis, F. R., \& Keating, P. (in press). Speech perception in dyslexic children with and without language impairments. In H. W. Catts \& A. G. Kamhi (Eds.), The connections between language and reading disabilities. Mahwah, NJ: Erlbaum.

Manis, F. R., Seidenberg, M. S., Doi, L. M., McBride-Chang, C., \& Petersen, A. (1996). On the bases of two subtypes of developmental dyslexia. Cognition, 58, 157-195.

Manis, F. R., Sperling, A. J., \& Lu, Z. L. (2004, June). Visual processing deficits in dyslexia in high noise displays. Paper presented at the meeting of the Society for the Scientific Study of Reading, Amsterdam.

Mather, N., \& Woodcock, R. W. (2001a). Examiner's manual. Woodcock-Johnson III tests of achievement. Itasca, IL: Riverside Publishing. 
Mather, N., \& Woodcock, R. W. (2001b). Examiner's manual. Woodcock-Johnson III tests of cognitive abilities. Itasca, IL: Riverside Publishing.

Medin, D. L., \& Schaffer, M. M. (1978). Context theory of classification learning. Psychological Review, 85, 207-238.

Nicolson, R. I., Fawcett, A. J., \& Dean, P. (2001). Developmental dyslexia: The cerebellar deficit hypothesis. Trends in Neuroscience, 9, 508-511.

Nissen, M. J., \& Bullemer, P. (1987). Attentional requirements of learning: Evidence from performance measures. Cognitive Psychology, 19, 1-32.

Nosofsky, R. M. (1986). Attention, similarity, and the identification-categorization relationship. Journal of Experimental Psychology, General, 115, 39-57.

Olson, R. K., Wise, B. W., Conners, F., Rack, J., \& Fulker, D. (1989). Specific deficits in component reading and language skills: Genetic and environmental influences. Journal of Learning Disabilities, 22, 339-348.

Paulesu, E., Démonet, J.-F., Fazio, F., McCrory, E., Chanoine, V., Brunswick, N., Cappa, S. F., Cossu, G., Habib, M., Frith, C. D., \& Frith, U. (2001). Dyslexia: Cultural diversity and biological unity. Science, 291, 2165-2167.

Pennington, B. F., \& Lefly, D. L. (2001). Early reading development in children at family risk for dyslexia. Child Development, 72, 816-833.

Rayner, K., Foorman, B. R., Perfetti, C. A., Pesetsky, D., \& Seidenberg, M. S. (2001). How psychological science informs the teaching of reading. Psychological Science in the Public Interest, 2, 31-74.

Reber, A. S. (1993). Implicit learning and tacit knowledge: An essay on the cognitive unconscious. (Oxford Psychology Series No. 19). New York: Oxford University Press.

Seidenberg, M. S., \& McClelland, J. L. (1989). A distributed, developmental model of word recognition and naming. Psychological Review, 96, 523-568.

Serniclaes, W., Sprenger-Charolles, L., Carré, R., \& Démonet, J.-F. (2001). Perceptual discrimination of speech sounds in developmental dyslexia. Journal of Speech, Language and Hearing Research, 44, 384-399.

Share, D. L. (1995). Phonological recoding and self-teaching: Sine qua non of reading acquisition. Cognition, 55, 151-218.

Sperling, A. J. (2004). Perceptual integration and noise exclusion in the etiology of developmental dyslexia. Unpublished doctoral dissertation, University of Southern California, Los Angeles, CA.

Sperling, A. J., Lu, Z. L., \& Manis, F. R. (2003, April). Magnocellular processing in reading: A study using phantom contour paradigm and first-order motion. Poster session presented at the annual meeting of the Cognitive Neuroscience Society, San Francisco, CA.

Stanovich, K. E. (1986). Matthew effects in reading: Some consequences of individual differences in the acquisition of literacy. Reading Research Quarterly, 21, 360-407.

Stanovich, K. E., \& Siegel, L. S. (1994). Phenotypic performance profile of children with reading disabilities: A regression based test of the phonological-core variable difference model. Journal of Educational Psychology, 86, 24-53.

Steffler, D. J. (2001). Implicit cognition and spelling development. Developmental Review, 21, 168-204.

Swan, D., \& Goswami, U. (1997). Phonological awareness deficits in developmental dyslexia and the phonological representations hypothesis. Journal of Experimental Child Psychology, 66, 18-41.

Talcott, J. B., Hansen, P. C., Assoku, E. L., \& Stein, J. F. (2000). Visual motion sensitivity in dyslexia: Evidence for temporal and energy integration deficits. Neuropsychologia 38, 935-943. 
Vicari, S., Marotta, L., Menghini, D., Molinari, M., \& Petrosini, L. (2003). Implicit learning deficit in children with developmental dyslexia. Neuropsychologia, 41, 108-114.

Wagner, R. K., \& Torgesen, J. K. (1987). The nature of phonological processing and its causal role in the acquisition of reading skills. Psychological Bulletin, 101, 192-212.

Werker, J., \& Tees, R. (1987). Speech perception in severely disabled and average reading children. Canadian Journal of Psychology, 41, 48-61.

Willcutt, E. G., Pennington, B. F., Boada, R., Ogline, J. S., Tunick, R. A., Chhabildas, N. A., \& Olson, R. K. (2001). A comparison of the cognitive deficits in reading disability and attention deficit/hyperactivity disorder. Journal of Abnormal Psychology, 110, 157-172.

Wimmer, H. (1993). Characteristics of developmental dyslexia in a regular writing system. Applied Psycholinguistics, 14, 1-33.

Wimmer, H., Mayringer, H., \& Landerl, K. (2000). The double-deficit hypothesis and difficulties in learning to read a regular orthography. Journal of Educational Psychology, 92, 668-680.

Witkin, H., Oltman, P., Raskin, E., \& Karps, S. (1971). A manual for the group-embedded figures test. Palo Alto, CA: Consulting Psychologists Press.

Wolff, P. H., Michel, G. F., Ovrut, M., \& Drake, C. (1990). Rate and timing precision of motor coordination in developmental dyslexia. Developmental Psychology, 26, 349-359.

Manuscript received April 14, 2004.

Accepted July 26, 2004. 